Article

\title{
The Fuzzy Process Quality Evaluation Model for the STB Quality Characteristic of Machining
}

\author{
Win-Jet Luo ${ }^{1}{ }^{\mathbb{D}}$, Kuen-Suan Chen ${ }^{2,3,4, *}$, Chun-Min $\mathrm{Yu}^{2, *}$ and Ting-Hsin $\mathrm{Hsu}^{5, *}$ \\ 1 Graduate Institute of Precision Manufacturing Technology, National Chin-Yi University of Technology, \\ Taichung 41170, Taiwan; wjluo@ncut.edu.tw \\ 2 Department of Industrial Engineering and Management, National Chin-Yi University of Technology, \\ Taichung 41170, Taiwan \\ 3 Department of Business Administration, Chaoyang University of Technology, Taichung 41349, Taiwan \\ 4 Institute of Innovation and Circular Economy, Asia University, 500, Lioufeng Rd., Wufeng, \\ Taichung 41354, Taiwan \\ 5 Department of Finance, National Taichung University of Science and Technology, Taichung 40401, Taiwan \\ * Correspondence: kschen@ncut.edu.tw (K.-S.C.); march@ncut.edu.tw (C.-M.Y.); \\ samhsu329@nutc.edu.tw (T.-H.H.); Tel.: +886-4-2392-4505 (K.-S.C.)
}

Received: 8 November 2020; Accepted: 19 November 2020; Published: 21 November 2020

\begin{abstract}
Whether it is important components of a machine tool itself or various important components processed by the machine tool, many vital quality characteristics mostly belong to the smaller-the-better type. When the process quality levels of these quality characteristics do not attain to the criteria, friction loss may increase during the machine operation, affecting not only the process precision and accuracy but also the lifetime of the product. Therefore, this study applied a smaller-the-better six-sigma quality index simultaneously demonstrating process quality level and process yield. Besides, in coping with statistical process control data, a one-tail confidence-interval-based fuzzy testing method was developed to evaluate process quality. Because this approach is built on the basis of confidence intervals, it can reduce the possibility of misjudgment resulting from sampling errors as well as integrate past experience to enhance the accuracy and precision of the assessment, and then it can grasp the timeliness of improvement.
\end{abstract}

Keywords: fuzzy process quality evaluation model; smaller-the-better; six-sigma; process yield; process quality

\section{Introduction}

Many studies on process technology and management have indicated that machine tools are assembled from a large number of components mainly used to process a variety of machinery equipment. Machine tools play a critical role in the entire machinery manufacturing industry, so that they are called the "Mother of Machinery" [1,2]. Whether it is important components of a machine tool itself or various important components processed by the machine tool, many important quality characteristics, including roundness, concentricity and squareness of the shaft and the bearing, are mostly of the smaller-the-better (STB) type. When the process quality levels of these quality characteristics are not good enough, friction loss may increase during the machine operation, which will affect the precision and accuracy of processing as well as the lifetime of the product.

Many statisticians and quality engineers have pointed out that Process Capability Indices (PCIs) are used as a very common process quality evaluation and analysis tool in the manufacturing industry. PCIs are not only a tool for selecting outsourcers but also a convenient and effective communication tool for internal process engineers and quality control engineers, which can assist with handling 
various problems concerning process technology or quality arising in the production process of products [3-8]. Furthermore, the scheme of six-sigma quality improvement initiated by Motorola can assist corporations with their quality improvement as well as reduce the defect rate for their products [9-12]. Therefore, the six-sigma quality improvement process contains significant implications for industry and is widely applied to manufacturing, aiming to enhance product quality levels as well as lower production defect rates [13-16].

Obviously, both Process Capability Indices and six-sigma quality levels are two significant tools in industry. Many scholars have explored the correlation between process capability indices and six-sigma quality levels [17-20]. Attempting to directly define quality level on the basis of an index value, Chang et al. [21] proposed the STB six-sigma quality index to evaluate the process quality of badminton racket handles. This STB six-sigma quality index can fully display the process quality level and the process yield. Therefore, it aims to appraise the process quality levels for the abovementioned STB quality characteristics, including roundness, concentricity and squareness of the shaft and the bearing.

Let random variable $X$ represent the process distribution for the STB quality characteristics. Assume that $X$ is distributed as a normal distribution using mean $\mu$ and standard deviation $\sigma$, i.e., $X \sim N\left(\mu, \sigma^{2}\right)$. Therefore, the STB six-sigma quality index can be denoted as follows:

$$
Q_{\mathrm{ISS}}=\frac{U S L-\mu}{\sigma}
$$

where USL stands for the upper specification limit. Obviously, the relationship between process yield (yield $\%$ ) and the value of quality index $Q_{\text {ISS }}$ is one-to-one, illustrated as follows:

$$
\begin{gathered}
\text { yield } \%=p\{X \leq U S L\} \\
=p\left\{Z \leq \frac{U S L-\mu}{\sigma}\right\} \\
=\int_{-\infty}^{Q_{I S S}} \frac{1}{\sqrt{2 \pi}} \times \exp \left\{-\frac{z}{2}\right\} d_{z} \\
=\Phi\left(Q_{\text {ISS }}\right)
\end{gathered}
$$

where $\Phi(\cdot)$ refers to the cumulative function of standard normal distributions. According to Chang et al. [21], when $\mu+k \sigma=U S L$, it means the process quality level for the STB quality characteristic attains to the quality level of $k$-sigma, that is

$$
Q_{\mathrm{ISS}}=\frac{U S L-\mu}{\sigma}=\frac{U S L-(\mu+k \sigma)}{\sigma}=k .
$$

Obviously, when the value of $Q_{\text {ISS }}$ equals $k$, the quality level is $k$ - sigma, and the process yield is $\Phi(k)$. For example, when $Q_{\text {ISS }}=3$, the quality level is $3-$ sigma, and it is guaranteed that the process yield will be $99.865 \%$.

According to many studies, the statistical hypothesis test of process capability can be performed as long as it is under statistical process control [22-25]. In an attempt to combine the verification of process capability with the accumulated professional knowledge of a team, the confidence-interval-based fuzzy testing method can be applied to evaluate the quality level during the manufacturing process $[7,17,18,26]$. Therefore, the upper confidence limit of quality index $Q_{\text {ISS }}$ is determined in Section 2. In Section 3, a one-tail confidence-interval-based fuzzy testing method is proposed to evaluate whether the process quality can meet the requirements of quality level. According to Chang et al. [21], since this approach is built based on confidence intervals, it can reduce the risk of misjudgment resulting from sampling errors. An empirical case is displayed in Section 4, aiming to show the applicability of the proposed method. Finally, conclusions are made in Section 5. 


\section{Upper Confidence Limit}

In reality, process mean $\mu$ and process standard deviation $\sigma$ are usually undetected. Therefore, they must be estimated from subsamples taken when the process is thought to be in control [11]. As noted by Montgomery [23], when $n>10$ or 12, a process mean and process standard deviation $(\bar{X}-S)$ control chart is often used and effectively reduces the standard deviation as well as the error of estimation. The estimation should usually be based on $m$ subsamples, where $m=20$ or 25 . Firstly, each subsample has $n$ observations of the STB quality characteristic; also, $m$ subsamples are available. As a result, let $\bar{X}_{h}$ and $S_{h}^{2}$ respectively denote the subsample mean and subsample variance of the $i$ th subsample below:

$$
\bar{X}_{h}=\frac{1}{n} \sum_{j=1}^{n} X_{h j}
$$

and

$$
S_{h}^{2}=\frac{1}{n-1} \sum_{j=1}^{n}\left(X_{h j}-\bar{X}_{h}\right)^{2}
$$

Let $N(N=m \times n)$ denote the total number of observations. We can use the overall sample mean and the pooled sample variance, which are the unbiased estimators, as follows:

$$
\overline{\bar{X}}=\frac{1}{m} \sum_{h=1}^{m} X_{h}
$$

and

$$
S^{2}=\frac{1}{m(n-1)} \sum_{h=1}^{m}(n-1) S_{h}^{2}=\frac{1}{m} \sum_{h=1}^{m} S_{h}^{2} .
$$

Therefore, the estimator of $Q_{\text {ISS }}$ can be shown as follows:

$$
\hat{Q}_{\mathrm{ISS}}=\frac{U S L-\overline{\bar{X}}}{S} .
$$

Under the assumption of normality, let

$$
K=\frac{m(n-1) S^{2}}{\sigma^{2}}=\sum_{h=1}^{m} \frac{(n-1) S_{h}^{2}}{\sigma^{2}}=\sum_{h=1}^{m} K_{h}
$$

where $K_{h}$ represents the chi-square distribution with $n-1$ degrees of freedom, and the characteristic function of $K_{h}$ is $\phi_{K_{h}}(t)=(1-2 i t)^{-(n-1) / 2}$. Therefore, the characteristic function of $K$ is

$$
\begin{gathered}
\phi_{K}(t)=E\left[e^{i t K}\right]=E\left[e^{i t \sum_{h}^{m} K_{h}}\right]=E\left[\prod_{h=1}^{m} e^{i t K_{h}}\right] \\
=\prod_{h=1}^{m} \phi_{k_{h}}(t)=\prod_{h=1}^{m}(1-2 i t)^{-(n-1) / 2} \\
=(1-2 i t)^{-m(n-1) / 2}
\end{gathered}
$$

and the distribution of $K$ is the chi-square distribution with $m(n-1)$ degrees of freedom (i.e., $\left.\chi_{m(n-1)}^{2}\right)$. Furthermore, the probability of $K$ smaller than $\chi_{1-\alpha / 2, m(n-1)}^{2}$ is $1-\alpha / 2$ and equivalent to

$$
P\left(\frac{S}{\sigma} \leq \sqrt{\frac{\chi_{1-\alpha / 2, m(n-1)}^{2}}{m(n-1)}}\right)=1-\frac{\alpha}{2}
$$


where $\chi_{1-\alpha / 2, m(n-1)}^{2}$ is the lower $1-\alpha / 2$ quantile of the chi-square distribution with $m(n-1)$ degrees of freedom. Next, to obtain the upper confidence limit from quality index $Q_{\text {ISS, }}$, we let

$$
\mathrm{Z}=\sqrt{m n} \times\left[Q_{\mathrm{ISS}}-\hat{Q}_{\mathrm{ISS}}\left(\frac{S}{\sigma}\right)\right]=\sqrt{m n} \times\left[\frac{\overline{\bar{X}}-\mu}{\sigma}\right]
$$

then $\mathrm{Z}$ is distributed as a standardized normal distribution (i.e., $\mathrm{Z} N(0,1)$ ). Therefore,

$$
p\left(\sqrt{N}\left(Q_{\text {ISS }}-\hat{Q}_{\text {ISS }} \times \frac{S}{\sigma}\right) \leq Z_{\alpha / 2}\right)=1-\frac{\alpha}{2} .
$$

Equivalently,

$$
P\left(Q_{\mathrm{ISS}} \leq \hat{Q}_{\mathrm{ISS}} \times \frac{S}{\sigma}+\frac{Z_{\alpha / 2}}{\sqrt{m n}}\right)=1-\frac{\alpha}{2}
$$

where $Z_{\alpha / 2}$ is the upper $\alpha / 2$ quantile of the standardized distribution. Both event $A$ and event $\mathrm{B}$ are defined as follows:

$$
\mathrm{A}=\left\{\frac{S}{\sigma} \leq \sqrt{\frac{\chi_{1-\alpha / 2, m(n-1)}^{2}}{m(n-1)}}\right\}
$$

and

$$
\mathrm{B}=\left\{Q_{I S S} \leq \hat{Q}_{I S S} \times \frac{S}{\sigma}+\frac{Z_{\alpha / 2}}{\sqrt{m n}}\right\} .
$$

Obviously, the probability for both event $A$ and event $B$ is equal to 1- $\alpha / 2$. Let the complement of event $A$ and the complement of event $B$ be displayed, respectively, as follows:

$$
\mathrm{A}^{C}=\left\{\frac{S}{\sigma}>\sqrt{\frac{\chi_{1-\alpha / 2, m(n-1)}^{2}}{m(n-1)}}\right\}
$$

and

$$
\mathrm{B}^{C}=\left\{Q_{I S S}>\hat{Q}_{I S S} \times \frac{S}{\sigma}+\frac{Z_{\alpha / 2}}{\sqrt{m n}}\right\} .
$$

Similarly, the probability for both event $\mathrm{A}^{C}$ and event $\mathrm{B}^{C}$ is equal to $\alpha / 2$. Based on Boole's inequality and DeMorgan's theorem, we learn that $P(\mathrm{~A} \cap \mathrm{B}) \geq 1-p\left(\mathrm{~A}^{\mathrm{C}}\right)-p\left(\mathrm{~B}^{\mathrm{C}}\right)$ and

$$
P\left\{Q_{I S S} \leq \hat{Q}_{I S S} \times \frac{S}{\sigma}+\frac{Z_{\alpha / 2}}{\sqrt{m n}}, \frac{S}{\sigma} \leq \sqrt{\frac{\chi_{1-\alpha / 2, m(n-1)}^{2}}{m(n-1)}}\right\} \geq 1-\alpha .
$$

Obviously, when $S / \sigma=\sqrt{\chi_{1-\alpha / 2, N-m}^{2} / m(n-1)}$,

$$
P\left\{Q_{\text {ISS }} \leq \hat{Q}_{\text {ISS }} \times \sqrt{\frac{\chi_{1-\alpha / 2, m(n-1)}^{2}}{m(n-1)}}+\frac{Z_{\alpha / 2}}{\sqrt{m n}}\right\} \geq 1-\alpha .
$$

Thus, the $(1-\alpha) \times 100 \%$ upper confidence limit on quality index $Q_{\text {ISS }}$ is

$$
U Q_{\mathrm{ISS}}=\hat{Q}_{\mathrm{ISS}} \times \sqrt{\frac{\chi_{1-\alpha / 2, m(n-1)}^{2}}{m(n-1)}}+\frac{Z_{\alpha / 2}}{\sqrt{m n}} .
$$




\section{Fuzzy Testing Method}

The advantage of the confidence-interval-based fuzzy evaluation method is that the original measurement method is used to collect data, which can improve the timeliness of data collection $[27,28]$. Next, the fuzzy number is constructed by means of the confidence interval, and then fuzzy evaluation rules are proposed according to the fuzzy number to increase the accuracy of evaluation. On the basis of this concept, this study directly used the measurement data of the control chart as the evaluation data. First, let $\left(x_{h, 1}, \ldots, x_{h, j}, \ldots, x_{h, n}\right)$ represent the observed values of $\left(X_{h, 1}, \ldots, X_{h, j}, \ldots, X_{h, n}\right)$ for $h=1$, $\ldots, \mathrm{m}$, and then observed values of $\bar{X}_{h}$ and $S_{h}$ can be shown, respectively, as follows:

$$
\bar{x}_{h}=\sum_{j=1}^{n} x_{h j}
$$

and

$$
s_{h}=\sqrt{\frac{1}{n} \sum_{j=1}^{n}\left(x_{h j}-\bar{x}_{h}\right)^{2}} .
$$

Therefore, the observed values of $\overline{\bar{X}}$ and $S$ are

$$
\overline{\bar{x}}=\frac{1}{m} \sum_{h=1}^{m} \bar{x}_{h}
$$

and

$$
s^{2}=\frac{1}{m} \sum_{h=1}^{m} s_{h}^{2}
$$

Obviously, the observed value of $U Q_{\text {ISS }}$ can be denoted as follows:

$$
U Q_{\mathrm{ISS} 0}=\hat{Q}_{\mathrm{ISS} 0} \times \sqrt{\frac{\chi_{1-\alpha / 2, m(n-1)}^{2}}{m(n-1)}}+\frac{Z_{\alpha / 2}}{\sqrt{m n}}
$$

where $\hat{Q}_{\text {ISS0 }}$ is the observed value of $\hat{Q}_{\text {ISS }}$ as follows:

$$
\hat{Q}_{\mathrm{ISS} 0}=\frac{U S L-\overline{\bar{x}}}{s} .
$$

Many studies have pointed out that a process capability evaluation is made based on the upper confidence limit of the index. Then, the null hypothesis $H_{0}$ is $Q_{\text {ISS }} \geq k$, and alternative hypothesis $H_{a}$ is $Q_{\text {ISs }}<k$. The statistical testing rules can be expressed as follows [26,29]:

(1) If $\hat{Q}_{\text {ISSO }} \geq k$, then $H_{0}$ is not rejected, and $Q_{\text {ISS }} \geq k$ is concluded.

(2) If $\hat{Q}_{\text {ISSO }}<k$, then $H_{0}$ is rejected, and $Q_{\text {ISS }}<k$ is concluded.

According to the above two statistical testing rules and the method introduced by Chen [29], a fuzzy testing method was developed on the basis of the upper confidence limit of the quality index. As suggested by Chen [29], the $\alpha$-cuts of the triangular fuzzy number $Q_{\text {ISS }}$ can be acquired below:

$$
\begin{gathered}
\tilde{\hat{Q}}_{\mathrm{ISS} 0}[\alpha]=\left\{\begin{array}{l}
{\left[\hat{Q}_{\mathrm{ISS} 0}(1), \hat{Q}_{\mathrm{ISS} 0}(\alpha)\right], \text { for } 0.01 \leq \alpha \leq 1} \\
\left.\hat{Q}_{\mathrm{ISS} 0}(1), \hat{Q}_{\mathrm{ISS} 0}(0.01)\right], \text { for } 0 \leq \alpha \leq 0.01
\end{array}\right. \\
U Q_{\mathrm{ISS} 0}=\hat{Q}_{\mathrm{ISS} 0} \times \sqrt{\frac{\chi_{1-\alpha / 2, m(n-1)}^{2}}{m(n-1)}+\frac{Z_{\alpha / 2}}{\sqrt{m n}}}
\end{gathered}
$$


where

$$
\begin{gathered}
\hat{Q}_{\mathrm{ISS} 0}(1)=\hat{Q}_{\mathrm{ISS} 0} \times \sqrt{\frac{\chi_{0.5, m(n-1)}^{2}}{m(n-1)}} \\
\hat{Q}_{\mathrm{ISS} 0}(\alpha)=\hat{Q}_{\mathrm{ISS} 0} \times \sqrt{\frac{\chi_{1-\alpha / 2, m(n-1)}^{2}}{m(n-1)}+\frac{Z_{\alpha / 2}}{\sqrt{m n}} .}
\end{gathered}
$$

Therefore, the half-triangular fuzzy number of $Q_{\text {ISS }}$ is $\tilde{\hat{Q}}_{\text {ISS0 }}=\left(Q_{I M}, Q_{I R}\right)$, where

$$
\begin{gathered}
Q_{I M}=\hat{Q}_{\text {ISS } 0} \times \sqrt{\frac{\chi_{0.5, m(n-1)}^{2}}{m(n-1)}} \\
Q_{I R}=\hat{Q}_{I S S 0} \times \sqrt{\frac{\chi_{0.995, m(n-1)}^{2}}{m(n-1)}+\frac{Z_{0.005}}{\sqrt{m n}} .}
\end{gathered}
$$

Therefore, the membership function of the fuzzy number $Q$ is

$$
\eta(x)=\left\{\begin{array}{lll}
0 & \text { if } & x<Q_{I M} \\
1 & \text { if } & x=Q_{I M} \\
\alpha & \text { if } & Q_{I M}<x<Q_{I R} \\
0 & \text { if } & x \geq Q_{I R}
\end{array}\right.
$$

where $\alpha$ is determined by

$$
x=\hat{Q}_{\mathrm{ISS} 0} \times \sqrt{\frac{\chi_{1-\alpha / 2, m(n-1)}^{2}}{m(n-1)}}+\frac{Z_{\alpha / 2}}{\sqrt{m n}} .
$$

In other words, when $\alpha=a$, the corresponding value of $x$ is $x_{0}$, that is $\eta\left(x_{0}\right)=a$. Therefore,

$$
x_{0}=\hat{Q}_{\mathrm{ISS} 0} \times \sqrt{\frac{\chi_{1-a / 2, m(n-1)}^{2}}{m(n-1)}}+\frac{Z_{a / 2}}{\sqrt{m n}} .
$$

Figure 1 presents a schematic diagram of membership function $\eta(x)$ with vertical line $x=k$.

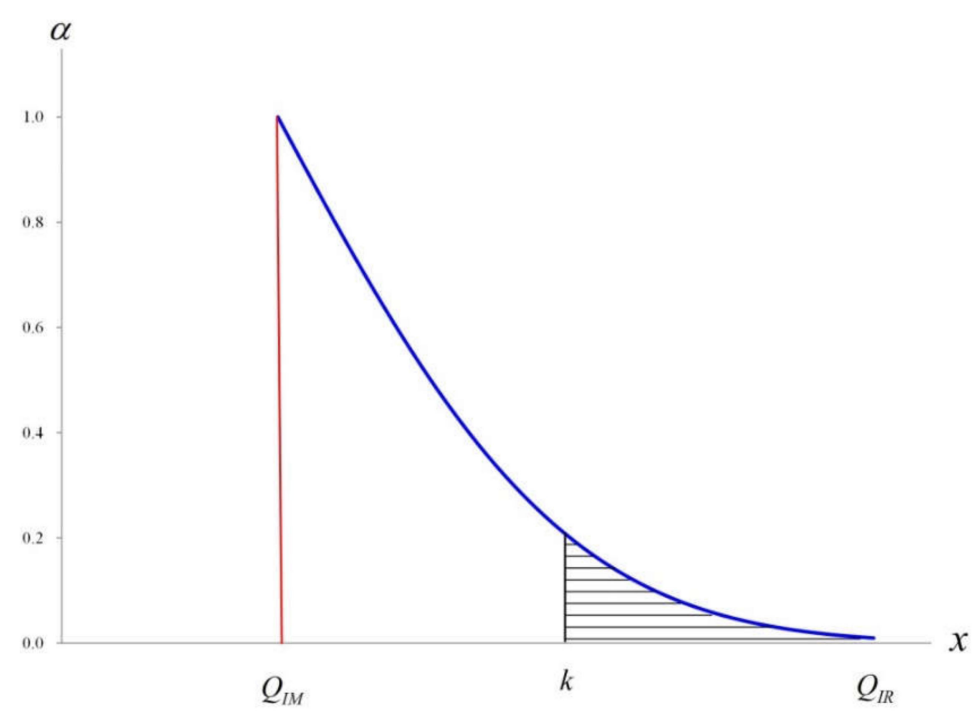

Figure 1. Schematic diagram of Membership function $\eta(x)$ with vertical line $x=k$. 
Let set $A_{T}$ be the area of the membership function $\eta(x)$, then

$$
A_{T}=\left\{(x, \alpha) \mid Q_{I M} \leq x \leq Q_{I R}(\alpha), 0 \leq \alpha \leq 1\right\} .
$$

As noted by Chen [29], we can calculate the double area of set $A_{T}$ as follows:

$$
a_{T}=2 \times \int_{Q_{I M}}^{Q_{I R}} \eta(x) d_{x} .
$$

Let set $A_{R}$ be the area of the membership function $\eta(x)$ on the right side of $x=k$, then

$$
A_{R}=\left\{(x, \alpha) \mid k \leq x \leq Q_{I R}(\alpha), 0 \leq \alpha \leq a\right\}
$$

where $\eta(k)=a$, and we can calculate the double area of set $A_{R}$ as follows:

$$
a_{R}=\int_{k}^{Q_{I R}} \eta(x) d_{x} .
$$

Regarding the $a_{R}$ as the numerator and the $a_{T}$ as the denominator, Buckley [30] used $a_{R} / a_{T}$ to perform fuzzy tests. Chen et al. [17] and Chen [29] simplified Buckley's method [30], replacing $a_{R} / a_{T}$ with $d_{R} / d_{T}$ to perform fuzzy tests, where $d_{R}=Q_{I R}-k$ and $d_{T}=2 \times\left(Q_{I R}-Q_{I M}\right)$ can be expressed as follows:

$$
\begin{gathered}
d_{R}=\hat{Q}_{\mathrm{ISS} 0} \times \sqrt{\frac{\chi_{0.995, m(n-1)}^{2}}{m(n-1)}}+\frac{Z_{0.005}}{\sqrt{m n}}-k \\
d_{T}=2 \times \hat{Q}_{\mathrm{ISS} 0} \times\left(\sqrt{\frac{\chi_{0.995, m(n-1)}^{2}}{m(n-1)}}-\sqrt{\frac{\chi_{0.5, m(n-1)}^{2}}{m(n-1)}}\right)+2 \times \frac{Z_{0.005}}{\sqrt{m n}} .
\end{gathered}
$$

Obviously, when $k<Q_{I M}$, then $d_{R} / d_{T}=0.5$. Besides, when $k>Q_{I R}$, then $d_{R} / d_{T}=0$. The fuzzy testing results in these two cases are consistent with statistical testing. When $d_{R} / d_{T} \in(0,0.5)$, then it is necessary to apply the fuzzy method proposed by this study to the evaluation. First, let $0<\phi_{1}<\phi_{2}<0.5$, where $\phi_{1}$ and $\phi_{2}$ can be determined by applying a previous data analysis or experts' accumulated experience. Many researchers believe that this model is more reasonable in practice than statistical testing [27-29]. Also, based on Chen et al. [17], the decision rules of fuzzy tests are listed below:

(1) If $d_{R} / d_{T} \leq \phi_{1}$, then reject $H_{0}$, and conclude $Q_{\text {IsS }}<k$.

(2) If $\phi_{1} \leq d_{R} / d_{T} \leq \phi_{2}$, then do not make a decision on reject/not reject.

(3) If $\phi_{2} \leq d_{R} / d_{T} \leq 0.5$, then do not reject $H_{0}$, and conclude $Q_{\text {ISS }} \geq k$.

\section{Case Study}

In this section, this study takes the gear grinding process conducted by a mechanical processing factory in central Taiwan as an example. Roundness is one of the important quality characteristics of the gear grinding process; the requirement for process quality of USL $=0.01 \mu \mathrm{m}$ must reach the five-sigma $(k=5)$ quality level. Subsequently, this study used the fuzzy testing rules proposed in Section 3 to appraise whether the process quality met the requirements of the five-sigma quality level. Based on Section 3, the assumptions for performing fuzzy testing can be denoted as follows:

Null Hypothesis $H_{0}: Q_{I S S} \geq 5$.

Alternative Hypothesis $H_{a}: Q_{\text {IsS }}<5$. 
Because the subsample size of the gear grinding process $\bar{X}-S$ control chart is $n=11,20$ sets of subsample data $(m=20)$ were taken to perform fuzzy testing under the control of the statistical process. Then, the observed values of $\overline{\bar{X}}$ and $S$ were calculated separately below:

$$
\begin{gathered}
\overline{\bar{x}}=\frac{1}{20} \sum_{h=1}^{20} \bar{x}_{h}=0.0082 \\
s=\sqrt{\frac{1}{20} \sum_{h=1}^{20} s_{h}^{2}}=0.00041 .
\end{gathered}
$$

Furthermore, the observed values of $\hat{Q}_{\text {ISS }}$ and $U Q_{\text {ISS }}$ were calculated as follows:

$$
\begin{gathered}
\hat{Q}_{\text {ISSO }}=\frac{U S L-\overline{\bar{x}}}{s}=\frac{0.01-0.0082}{0.00041}=4.39 \\
U Q_{\text {ISSO }}=\hat{Q}_{\text {ISSO }} \times \sqrt{\frac{\chi_{0.995,200}^{2}}{200}}+\frac{Z_{0.005}}{\sqrt{220}}=4.39 \times \sqrt{\frac{255.26}{200}}+\frac{2.576}{\sqrt{220}}=5.13 .
\end{gathered}
$$

Based on Equations (30) and (31), we derived the observed values of $Q_{I M}$ and $Q_{I R}$ from the following equations:

$$
\begin{gathered}
Q_{I M}=\hat{Q}_{I S S 0} \times \sqrt{\frac{\chi_{0.5,200}^{2}}{200}}=4.39 \times \sqrt{\frac{199.33}{200}}=4.38 \\
Q_{I R}=\hat{Q}_{\text {ISSO }} \times \sqrt{\frac{\chi_{0.995,200}^{2}}{200}}+\frac{Z_{0.005}}{\sqrt{200}}=4.39 \times \sqrt{\frac{255.26}{200}}+\frac{2.576}{\sqrt{220}}=5.13 .
\end{gathered}
$$

Consequently, the half-triangular fuzzy number of $Q_{\mathrm{ISS}}$ was $\widetilde{\hat{Q}}_{\mathrm{ISS} 0}=(4.38,5.13)$, and the membership function of the fuzzy number $\widetilde{\hat{Q}}_{\text {ISS0 }}$ was

$$
\eta(x)=\left\{\begin{array}{lll}
0 & \text { if } & x<4.38 \\
1 & \text { if } & x=4.38 \\
\alpha & \text { if } & 4.38<x<5.13 \\
0 & \text { if } & x \geq 5.13
\end{array} .\right.
$$

Figure 2 presents a diagram of Membership function $\eta(x)$ with vertical line $x=5$.

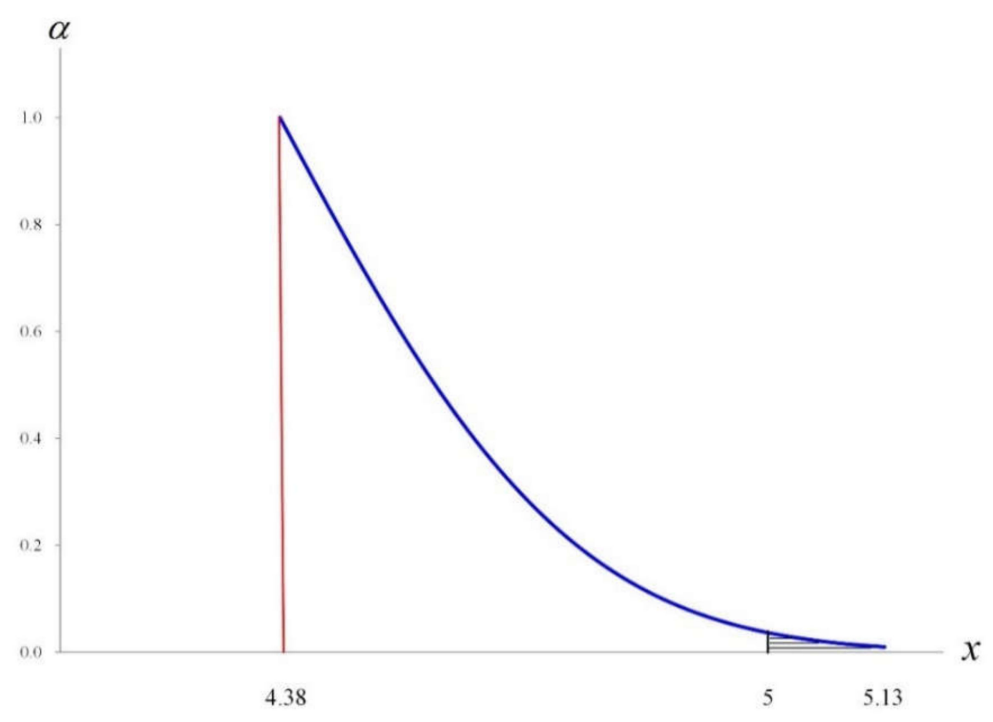

Figure 2. Membership function $\eta(x)$ with vertical line $x=5$. 
Obviously, according to the above statistical test rule (1), when the observed value $U Q_{\text {ISS0 }}=5.13$ $\geq 5$ (the required quality level is five-sigma), then $H_{0}$ was not rejected, and $Q_{\text {ISS }} \geq 5$ was concluded. In fact, $\hat{Q}_{\text {ISS0 }}=4.39$ was much smaller than the five-sigma quality level. Next, based on Equations (37) and (38), we calculated the value of $d_{R}$ and $d_{T}$ as follows:

$$
\begin{gathered}
d_{R}=4.39 \times \sqrt{\frac{\chi_{0.995,200}^{2}}{200}}+\frac{Z_{0.005}}{\sqrt{220}}-5=0.13 \\
d_{T}=2 \times \hat{Q}_{\mathrm{ISS} 0} \times\left(\sqrt{\frac{\chi_{0.995,200}^{2}}{200}}-\sqrt{\frac{\chi_{0.5,200}^{2}}{200}}\right)+2 \times \frac{Z_{0.005}}{\sqrt{220}} \\
=2 \times 4.39 \times\left(\sqrt{\frac{255.26}{200}}-\sqrt{\frac{199.33}{200}}\right)+2 \times \frac{2.576}{\sqrt{220}} \\
=2 \times 4.39 \times 0.1314+2 \times 0.1736 \\
=1.50 .
\end{gathered}
$$

Therefore, $d_{R} / d_{T}=0.087$. Take $\phi_{1}=0.2$ and $\phi_{2}=0.4$. Based on the decision rule (1) of fuzzy testing, when $d_{R} / d_{T}=0.087<\phi_{1}$, then reject $H_{0}$ and conclude that $Q_{\text {ISS }}<5$. According to Chen et al. [17] and Chen [29], the fuzzy testing method suggested by this study seems to be more reasonable than statistical inference.

\section{Conclusions}

The STB quality characteristics are significant quality characteristics for many machined products. Enhancing the process quality level of these quality characteristics will reduce friction loss during machine operation in order to improve the precision, accuracy and product life of the processed products. This study employed STB six-sigma quality indices and combined them with statistical process control data, developing a one-tail confidence-interval-based fuzzy testing approach to appraise process quality. Not only can the six-sigma quality indices simultaneously mirror the process quality level but can also reveal the process yield. In addition, the fuzzy testing model offered by this study was built on the basis of confidence intervals, so the model can reduce the possibility of misjudgment due to sampling errors and enhance the accuracy and precision of the assessment according to the accumulated data and past experience. This approach can help industry accurately grasp the timeliness of improvement. Finally, an empirical case was adopted to demonstrate the application of the method suggested by this study. From the case study, it was clearly seen that the fuzzy testing model presented by this study seemed to be more reasonable than statistical inference.

Plenty of process quality evaluations are carried out using statistical process control data. For the sake of timeliness, some are evaluated via simple random sampling. The method adopted by this study belongs to the approach using statistical process control data. It is recommended that the proposed corresponding fuzzy testing rules based on simple random sampling rules be used in the future. In addition, the method suggested by this study can also be extended to process quality evaluations and analyses of bilateral specifications.

Author Contributions: Conceptualization, W.-J.L. and K.-S.C.; methodology, W.-J.L. and K.-S.C.; software, C.-M.Y.; validation, T.-H.H.; formal analysis, W.-J.L. and K.-S.C.; resources, T.-H.H.; data curation, C.-M.Y. and T.-H.H.; writing-original draft preparation, W.-J.L., K.-S.C., C.-M.Y. and T.-H.H.; writing-review and editing, W.-J.L., K.-S.C. and C.-M.Y.; visualization, T.-H.H.; supervision, W.-J.L. and K.-S.C.; project administration, K.-S.C. and C.-M.Y. All authors have read and agreed to the published version of the manuscript.

Funding: This research received no external funding.

Conflicts of Interest: The authors declare no conflict of interest. 


\section{References}

1. Chen, K.S.; Yu, C.M.; Hsu, T.H.; Cai, S.R.; Chiou, K.C. A model for evaluating the performance of the bearing manufacturing process. Appl. Sci. 2019, 9, 3105. [CrossRef]

2. Shinno, H.; Yoshioka, H.; Sawano, H. A framework for systematizing machine tool engineering. Int. J. Autom. Technol. 2013, 7, 760-768. [CrossRef]

3. Besseris, G.J. Evaluation of robust scale estimators for modified Weibull process capability indices and their bootstrap confidence intervals. Comput. Ind. Eng. 2019, 128, 135-149. [CrossRef]

4. Chang, T.C.; Wang, K.J.; Chen, K.S. Capability performance analysis for processes with multiple characteristics using accuracy and precision. Proc. Inst. Mech. Eng. Part B J. Eng. Manuf. 2014, 228, 766-776. [CrossRef]

5. Chen, K.S. Estimation of the process incapability index. Commun. Stat. Theory Methods. 1998, 27, $1263-1274$. [CrossRef]

6. Dharmasena, L.S.; Zeephongsekul, P. A new process capability index for multiple quality characteristics based on principal components. Int. J. Prod. Res. 2016, 54, 4617-4633. [CrossRef]

7. Yu, C.M.; Chen, K.S.; Lai, K.K.; Hsu, C.H. Fuzzy Supplier Selection Method Based on Smaller-The-Better Quality Characteristic. Appl. Sci. 2020, 10, 3635. [CrossRef]

8. Yu, C.M.; Lai, K.K.; Chen, K.S.; Chang, T.C. Process-quality evaluation for wire bonding with multiple gold wires. IEEE Access. 2020, 8, 106075-106082. [CrossRef]

9. Hoskin, J.; Stuart, B.; Taylor, J. A Motorola Commitment: A Six Sigma Mandate, The Motorola Guide to Statistical Process Control for Continuous Improvement Towards Six Sigma Quality; Motorola Co.: Schaumburg, IL, USA, 1988.

10. Linderman, K.; Schroeder, R.G.; Zaheer, S.; Choo, A.S. Six Sigma: A goal-theoretic perspective. J. Oper. Manag. 2003, 21, 193-203. [CrossRef]

11. Chen, K.S.; Wang, K.J.; Chang, T.C. A novel approach to deriving the lower confidence limit of indices cpu, cpl, and cpk in assessing process capability. Int. J. Prod. Res. 2017, 55, 4963-4981. [CrossRef]

12. Yu, K.T.; Sheu, S.H.; Chen, K.S. The evaluation of process capability for a machining center. Int. J. Adv. Manuf. Technol. 2007, 33, 505-510. [CrossRef]

13. Anderson, N.C.; Kovach, J.V. Reducing welding defects in turnaround projects: A lean six sigma case study. Qual. Eng. 2014, 26, 168-181. [CrossRef]

14. Huang, C.F.; Chen, K.S.; Sheu, S.H.; Hsu, T.S. Enhancement of axle bearing quality in sewing machines using six sigma. Proc. Inst. Mech. Eng. B J. Eng. Manuf. 2010, 224, 1581-1590. [CrossRef]

15. Sharma, M.; Sharma, S.; Sahni, S. Structured problem solving: Combined approach using 8d and six sigma case study. Eng. Manag. Prod. Serv. 2020, 12, 57-69.

16. Su, C.T.; Su, F.M.; Chen, T.Y.; Chen, L.F. Enhancing the structural strength of an ODD laptop via six sigma approach. IEEE Trans. Compon. Packaging Manuf. Technol. 2019, 9, 2200-2209. [CrossRef]

17. Chen, K.S.; Wang, C.H.; Tan, K.H. Developing a fuzzy green supplier selection model using six sigma quality indices. Int. J. Prod. Econ. 2019, 212, 1-7. [CrossRef]

18. Chen, K.S.; Chang, T.C. Construction and fuzzy hypothesis testing of Taguchi Six Sigma quality index. Int. J. Prod. Res. 2020, 58, 3110-3125. [CrossRef]

19. Wang, C.H.; Chen, K.S. New process yield index of asymmetric tolerances for bootstrap method and Six Sigma approach. Int. J. Prod. Econ. 2020, 219, 216-223. [CrossRef]

20. Yu, K.T.; Chen, K.S. Testing and analysing capability performance for products with multiple characteristics. Int. J. Prod. Res. 2016, 54, 6633-6643. [CrossRef]

21. Chang, T.C.; Chen, K.S.; Yu, C.M. Process quality assessment model of hand tools: A case study on the handle of ratchet torque wrench. Int. J. Reliab. Qual. Saf. Eng. 2016, 23, 1650017. [CrossRef]

22. Faraz, A.; Heuchenne, C.; Saniga, E.; Foster, E. Monitoring delivery chains using multivariate control charts. Eur. J. Oper. Res. 2013, 228, 282-289. [CrossRef]

23. Montgomery, D.C. Introduction to Statistical Quality Control, 7th ed.; Wiley: New York, NY, USA, 2012.

24. Chen, K.S.; Chen, D.F.; Huang, M.C.; Chang, T.C. Analyzing processing quality of machine tools via processed product: Example of ball valve processing machine. Proc. Inst. Mech. Eng. Part E-J. Process Mech. Eng. 2020, 234, 331-341. [CrossRef]

25. Wu, M.F.; Chen, H.Y.; Chang, T.C.; Wu, C.F. Quality evaluation of internal cylindrical grinding process with multiple quality characteristics for gear products. Int. J. Prod. Res. 2019, 57, 6687-6701. [CrossRef] 
26. Chen, K.S. Fuzzy testing decision-making model for intelligent manufacturing process with Taguchi capability index. J. Intell. Fuzzy Syst. 2020, 38, 2129-2139. [CrossRef]

27. Yu, C.H.; Liu, C.C.; Chen, K.S.; Yu, C.M. Constructing Fuzzy Hypothesis Methods to Determine Critical-To-Quality Service Items. Mathematics 2020, 8, 573. [CrossRef]

28. Chen, K.S.; Yu, C.M. Fuzzy test model for performance evaluation matrix of service operating systems. Comput. Ind. Eng. 2020, 140, 106240. [CrossRef]

29. Chen, K.S. Fuzzy testing of operating performance index based on confidence intervals. Ann. Oper. Res. 2019. [CrossRef]

30. Buckley, J.J. Fuzzy statistics: Hypothesis testing. Soft Comput. 2005, 9, 512-518. [CrossRef]

Publisher's Note: MDPI stays neutral with regard to jurisdictional claims in published maps and institutional affiliations.

(C) 2020 by the authors. Licensee MDPI, Basel, Switzerland. This article is an open access article distributed under the terms and conditions of the Creative Commons Attribution (CC BY) license (http://creativecommons.org/licenses/by/4.0/). 